\title{
Bus Station Fees Unit Root Testing during A Transition Time: A Time-series Microeconomics Development, Consistencies and Theoretical Unification
}

\author{
Agung Riyardi ${ }^{1}$, Ihwan Susila ${ }^{2}$, Sujadi $^{3}$, Triyono ${ }^{4}$ \\ ${ }^{1}$ Economics Department, Universitas Muhammadiyah Surakarta, Indonesia, Agung.Riyardi@ ums.ac.id \\ ${ }^{2}$ Management Department, Universitas Muhammadiyah Surakarta, Indonesia, Ihwan.Susila@ums.ac.id \\ ${ }^{3}$ Management Department, Universitas Muhammadiyah Surakarta, Indonesia, Sujadi@ums.ac.id \\ ${ }^{4}$ Economics Department, Universitas Muhammadiyah Surakarta, Indonesia, Triyono@ums.ac.id
}

\begin{abstract}
This paper employs three unit root tests to the daily fees of Tirtonadi Bus Station in Surakarta, Indonesia. The fee consists of Passenger, Parking, Short-distance bus and Long-distance bus fees. The data were collected from transition period starting November until December 2016. The research reveals two findings. The first is regarding the fees. All fees are found to be persistent and are useful. The second is regarding Augmented Dickey-Fuller (ADF), Phillips-Perron (PP) and Ng-Perron (NP) unit root tests. They confirm error variance estimation at zero frequency, detrending estimation and optimal lag selection. All of the results open opportunities to time-series microeconomics practice and studying. In addition, they are an example of consistencies and the theoretical unification
\end{abstract}

Key words: Bus Station Fee, Theoretical Consistency and Unification, Time-series Microeconomics, Unit Root Tests.

\section{INTRODUCTION}

Time-series data can contain a root and be not a random walk data. Using such a time-series data leads to a spurious regression equation. Furthermore, it causes misinterpretations and flawed analyses. To avoid the problem, time-series data should be stationary: Its mean, variance and co-variance should be constant across time and do not depend on time. [1] and [2].

In the beginning, the unit root test was applied to the forecasting field. [3]. After that, the formal unit root tests were developed to cover four interdependent specifications: Deterministic trend, lag length, stability, and homoscedasticity specifications. [4]. As a result, there are six formal unit root tests. [2]. All of them can be divided into 2 big groups. The first group assumes that time-series data contains root. It consists of the Dickey-Fuller/Augmented Dickey-Fuller (DF/ADF); Phillips and Perron (PP); Dickey-Fuller Generalized Least Square (DF GLS); Elliott, Rothenberg and Stock (ERS); and Ng and Perron (NP) tests.
The second group is the Kwiatkowski, Phillips, Schmidt, and Shin (KPSS) test. It assumes that the data is stationary. [5].

All tests in the first group can be regrouped into three subgroups. The first sub group is the DF test and its modification. It consists of DF/ADF and DF GLS tests. The DF test employs the first-order autoregressive process, while the ADF test improves the DF test to solve the autocorrelation problem. The ERS test is a part of DF test. It is similar to the DF GLS test [5]. The second subgroup is the PP test. The test solves the autocorrelation and heteroscedasticity problems. [6]. The third subgroup is the NP test. The test develops the unit root test based on a detrending data. [4] and [5]. In addition, the test provides the information criteria modification [7].

All of the statistical tests in the first sub groups are related each other. The ADF formula is the DF formula that is similar to student-t test. The PP formula develops the $t$ test called the $\mathrm{Zt}$ test. It contains consistent estimate of the error variance and error variance at frequency zero. Based on the the Bartlett kernel estimator, the error variance estimator at zero frequency is to estimate the Newey West Heteroscedasticity Autocorrelation Estimator (HAC). When the error variance and error variance at frequency zero are similar, the $\mathrm{Zt}$ reduced to the $\mathrm{t}$ test. In addition, The $\mathrm{Zt}$ can be obtained from the $Z \alpha$ and SB tests Multiplication. The NP test develops the PP formula. The NP test demeans the time trend data and modifies the information criterion so that $\mathrm{Zt}, \mathrm{Z} \alpha$ and $\mathrm{SB}$ tests change to MZt, MZ $\alpha$ and MSB tests.

The unit root test has an important role in the time-series econometrics. It examines single macroeconomic persistent variable, a breakpoint variable, a panel data variable and relates to cointegration test. Its role to variable with breakpoint emerged the theory of structural change, unit root and trend breaks, and fractional integration or an empirical study of a structural change. [8]. Its role to a panel data developed at least four types of panel data unit root tests: Levin-Lin, Im-Pesaran-Shin and Maddala-Wu tests and the panel analysis of non-stationary idiosyncratic and common components (PANIC) residual test. [9] and [10]. In addition, it is a strategic test in the cointegration test because it is an engine for the cointegration test and should be done first before the cointegration test. [11] and [12]. 
However, the test is rarely applied to the microeconomic context, although time-series data are also found in microeconomic contexts, such as profit, revenue and cost time-series data. The time range in the microeconomic field is more varied than that in the macroeconomic or aggregation data field. The firm data can be daily, weekly, monthly or yearly data, while the aggregate data are rarely daily or weekly data. In addition, the time-series data are more plentiful in the microeconomic field than in the macroeconomic field. A two-month observation generates sixty daily microeconomic data sets, whereas generating 60 monthly macroeconomic data sets requires 5 years of observation.

We are interested in confirming the unit root of a single microeconomic time-series data set, so we have studied fees charged in the Tirtonadi Bus Station, Surakarta, Indonesia during the transition time between November and December 2016. We assume that the fee is a common Bus Station revenue source [13]. Even, it is common in other types of station such as the port terminal called a dynamic concession fee [14] or the airport called a passenger service charge [15]. In addition, we assume that it is similar to the revenue in the microeconomics context: It should be stable and grow over time. Moreover, it is an efficient and effective revenue [16]. The Bus Station fee is a persistent fee and can be tested by unit root tests.

We assume that Tirtonadi Bus Station is an important public infrastructure. Such as other infrastructures it has direct and indirect impacts. This is can be known from many studies that found the important of infrastructure. Talib, Sulieman, \& Prihatmanti [17] for example, found that the quality of public infrastructure can attract tourists to kota Aur Malaysia. Francisco D. Esponilla II et al. [18] observed issues and challenges faced by Philippines small business in using internet infrastructure

Furthermore, we assume that a fee as a revenue is organizational performance that should be checked. Many studies evaluate the organizational performance. Deshmukh \& Borade [19] and Caryl Charlene Escolar-Jimenez et al. [20] for examples, evaluate performance. The first evaluates Indian plastic industry performance based on lean and green concepts, while the second evaluate employees compensation based on their performance..

We strengthen our assumption by the Bus Station transition time. Since 2017, the Bus Station has been taken over by the central government from the Surakarta City authority. We assume months before the transition time as a critical periods that strengthen the persistent fee. The transition time is different from the centralized to decentralized regimes in Post-Soviet as analyzed by [21]. In addition, the transition time is different from the administrative reforms that the traditional culture impeded the new public management as studied by [22]. In other words, we assume that the Bus Station treated the transition period as a positive interval and not an uncertain interval. In this transition period, the Bus Station operated normally, including the charging of fee. The Bus Station Passenger, Parking, Long-distance bus and Short-distance bus fees were charged efficiently and effectively as usual so that the fees were stable and growing. All of fees are persistent.

Many studies focus on microeconomic time-series data. There are three groups. The first group employs microeconomics as a tool of analysis, although the data are a macroeconomic time-series data set such as by [23], [24] or [25]. The second group studies microeconomic time-series data such as by [26], [27] or [28]. The third group studies microeconomic time-series data and employs unit root tests such as by [29], [30], [31], and [32].

Looking in-depth to the third group we found that researchers above observed varied microeconomic variables such as product, price, revenue, cost and profit. Some of them observe the microeconomic variables under the persistence flag based on panel data unit root tests as [29] and [31], while others prefer to estimate time-series microeconomics models and employs ADF and PP tests as [30] and [32]. Their studies strengthen the third group but they are different from the pure time-series microeconomic persistent variable examination study.

To the best of our knowledge, no research that observes the pure time-series microeconomic persistent variable based on the unit root test. In addition, no research in this third group that employs NP unit root test. We are interested to employ NP test together to ADF and PP tests. We hope that our work develops time-series microeconomics from microeconomics and econometrics sides. Moreover, we hope that our work is an example of theoretical consistencies and unification.

The aim of our work is to employ three unit root tests to persistent fees. It means that we concern with the output and method. Our concern with the output lies on the persistent fees analysis, while our concern with the method lies on the unit root test analysis. In addition, we concern to develop the time-series microeconomics relates, to a theory-data coherency and theoretical unification.

Our output finding shows that all of fees are persistent fees. Bus Station Parking, Long-distance bus and Short-distance bus fees passed all unit root tests easily, while the Passenger fee passed heavily unit root tests. Persistent fees confirmed that they are efficient, effective, stable and growing fees in the transition time. Another finding is about unit root testing method. We confirmed the ADF, PP and NP tests. Employing them should recognize to the error variance estimation at zero frequency, detrending estimation and lag selection. The findings place us in the third group of the time-series microeconomics studying. Moreover, we give an example of a theory-data coherency from internal and external consistencies, and an example of the theoretical unification from the concept-method combination.

Our research opens a new opportunity in the practical and development aspects. Firms and organization can practice useful revenue and testing it periodically. In addition, the third time-series microeconomics group can conducts future researches about persistent microeconomic variable in many fields based on unit root tests. If recognizing to coherencies 
and unification, then the development brings an example to a theory-data coherency and theoretical unification.

Section 2 explains the method. The procedure for executing unit root tests is explained. Section 3 demonstrates the results and provides discussions. Comparing to other researches, our position is placed and some suggestions are offered.

\section{METHODOLOGY}

Our materials were Tirtonadi Bus Station daily fees during transition time. There were four fees: Passenger, Parking, Long-distance and Short-distance bus fees. The transition time was 3 months before 2017, before the Bus Station handled by the Indonesian Central Government.

Tirtonadi Bus Station is located in Surakarta city, Central Java province, Indonesia. We observed it because it is a special bus station. It is a model of an Indonesian big bus station.

Our method were unit root testing. It was done by ADF, PP and NP tests. Three things were conducted: Specifying an augmented autoregressive (AR) equation, preparing the statistic and its critical value, and evaluating the unit root.

The augmented AR equation was specified based on the drift and the drift and trend equations. They were expressed by Equation 1 to 4 . They were simplified from eight equations.

$$
\begin{aligned}
& \Delta \operatorname{lnPs} s_{\mathrm{t}}=\beta_{1} \ln \mathrm{Ps}_{\mathrm{t}}+\text { D. } \beta_{2} \mathrm{tlnPs}_{\mathrm{t}}+\alpha \ln \mathrm{Ps}_{\mathrm{t}-1}+ \\
& \delta_{\mathrm{i}} \sum_{\mathrm{i}=1}^{\mathrm{p}} \Delta \ln \mathrm{Ps}_{\mathrm{t}-1}+\varepsilon \ln \mathrm{Ps}_{\mathrm{t}} \\
& \Delta \operatorname{lnPk_{\mathrm {t}}}=\dot{\beta}_{1} \ln \mathrm{Pk} \mathrm{t}_{\mathrm{t}}+\text { D. } \dot{\beta}_{2} \mathrm{tlnPk}_{\mathrm{t}}+\dot{\alpha} \ln \mathrm{Pk}_{\mathrm{t}-1}+ \\
& \dot{\delta}_{\mathrm{i}} \sum_{\mathrm{i}=1}^{\mathrm{p}} \Delta \ln \mathrm{Pk}_{\mathrm{t}-1}+\dot{\varepsilon} \ln \mathrm{Pk}_{\mathrm{t}} \\
& \Delta \operatorname{lnFd} d_{t}=\ddot{\beta_{1}} \ln \mathrm{Fd}_{\mathrm{t}}+\text { D. } \ddot{\beta_{2}} \operatorname{tn} \mathrm{Fd}_{\mathrm{t}}+\ddot{\alpha} \ln \mathrm{Fd}_{\mathrm{t}-1}+ \\
& \ddot{\delta}_{\mathrm{i}} \sum_{\mathrm{i}=1}^{\mathrm{p}} \Delta \ln \mathrm{Fd}_{\mathrm{t}-1}+\ddot{\varepsilon} \ln \mathrm{Fd}_{\mathrm{t}} \\
& \Delta \operatorname{lnSd_{t}}=\dddot{\beta}_{1} \ln S d_{t}+\text { D. } \dddot{\beta}_{2} t \ln S d_{t}+\dddot{\alpha} \ln S d_{t-1}+ \\
& \dddot{\delta}_{\mathrm{i}} \sum_{\mathrm{i}=1}^{\mathrm{p}} \Delta \ln \mathrm{Sd}_{\mathrm{t}-1}+\dddot{\varepsilon}_{\mathrm{Sd}}
\end{aligned}
$$

The Ps is the Passenger fee, $\mathrm{Pk}$ is the Parking fee, $\mathrm{Fd}$ is the Long-distance bus fee and $\mathrm{Sd}$ is the Short-distance bus fee. The Ln means a natural logarithm value. The $\Delta$ is the first-difference operation/equation that is derived from the level operation/equation. The value of $d$ is 0 and 1 . Setting $d$ equals to 0 leads to a drift equation, while setting $d$ equals to 1 leads to a drift and trend equation. The $\beta_{1}$ coefficient is the drift coefficient, the $\beta_{2} t$ coefficient is the trend coefficient. The $\alpha$ is equal to $\rho-1$, the $\rho$ is the autoregressive coefficient that is assumed between -1 and 1 , the $\delta$ is the lag coefficient. The pure (without dot), dot one, two and three above coefficients and error term differentiate coefficients and error term. The $\mathrm{i}$ is the number of the lag length, the $\mathrm{p}$ is the maximum number of the lag length, and the $\varepsilon$ is the white noise error term.

Statistics of as were obtained by ADF, PP and NP tests. Equation 5 is the formula to estimate the $\alpha$ statistics based on $\mathrm{ADF}$ test, Equation 6 is the formula to estimate the $\alpha$ statistics based on PP test, and Equation 7 is the formula to estimate the $\alpha$ statistics based on NP test. They can be applied for Equation 1 to 4 .

$t_{\alpha}=\frac{\dot{\alpha}}{S(\dot{\alpha})}$

$\mathrm{Z}_{t}=t_{\alpha}\left(\frac{\gamma_{0}}{f_{0}}\right)^{\frac{1}{2}}-\frac{T\left(\gamma_{0}-f_{0}\right)(S(\alpha))}{2 f_{0}^{\frac{1}{2}} S}$

$\mathrm{MZ}_{\mathrm{t}}^{\mathrm{d}}=M Z_{\alpha}^{d} \mathrm{XMSB}^{d}$

The $\mathrm{t}$ is the $\mathrm{t}$ statistic, $\alpha$ is the expected $\alpha, \mathrm{S}$ is an abbreviation of the standard error, $Z_{t}$ is the modified $t$ statistic proposed by PP test, $\gamma_{0}$ is the error variance estimator, and $\mathrm{f}_{0}$ is the error variance estimator at zero frequency. The $\mathrm{MZ}_{\mathrm{t}}^{\mathrm{d}}$ is the modified $\mathrm{Z}_{\mathrm{t}}$. The modification was done by employing a detrended equation and modifying the information criterion, M. The detrended equation modification was done by imposing the AR estimator to estimate the HAC. As a result as shown by (7) $M Z_{t}^{\mathrm{d}}=M Z_{\alpha}^{d} \mathrm{X} M S B^{d}$, where $M Z_{\alpha}^{d}$ is the modification of $\mathrm{Z}_{\alpha}$ in the PP test and $M S B^{d}$ is the modification of the Bhargava statistic. The availability of two detrended equation types--the Ordinary Least Square (OLS) and Generalized Least Square (GLS) detrended equations--allows us to choose one of them. The information criterion modification was done by considering to $M P_{t}^{d}$ which is a modified optimal point statistic from the ERS optimal point. The availability of many types of information criterion and their modifications enables us to choose to the Schwarz Information Criterion (SIC) and the Modified Schwarz Information Criterion (MSIC).

Critical values of $\alpha$ s was obtained from McKinnon and NP Tables at 1\%,5\% and $10 \%$ levels. Critical values obtained from McKinnon Table were compared to statistics from ADF and PP tests. Critical values obtained from NP test were compared to statistics from NP test.

Evaluation was done by setting the null hypothesis that $\alpha \mathrm{s}=0$. Rejection of the hypothesis meant that the variable does not contain a unit root, while its acceptance meant that the variable contains a unit root. The null hypothesis rejection was decided when the $\alpha$ absolute statistical value exceeds its critical value.

\section{RESULTS AND DISCUSSION}

We found two results. The first is about the output of the unit root testing. The second is about the method. The Parking, Long-distance bus and Short-distance bus fees root was easily rejected by ADF, PP and NP tests. However, the Passenger fee root was easily rejected only by PP test, whilst the passenger root fee is heavily rejected by ADF and NP tests. (See stars in Table 1, 2 and 3). Even, the passenger root fee was failed to be rejected by the ADF test at Level Equations. The information criterion was modified using MSIC to increase its absolute statistic, but it was still lower than its critical value (See "LnPassenger" at Table 1). 
Agung Riyardi et al., International Journal of Emerging Trends in Engineering Research, 7(11), November 2019, 403 - 409

The unit root of all fees was easily rejected by PP test (See Table 2). However, the Passenger fee was different from others. Its root was rejected at $10 \%$ critical value for Level Equation, whereas others were rejected at $1 \%$ critical value.

The unit root of the Parking, Long-distance bus and Short-distance bus fees was easily rejected by the NP test, while the Passenger fee unit root testing came to mixed results

Regardless to the different statistical processes to proof their persistence, all of fees therefore, are persistent fees. They have two features. First, they are joint fees that consist of
(See Table 3). First differentiating for all Equations did not result to root rejecting. The passenger fee unit root at the First-difference Equations was rejected only when two changing were imposed. The first is changing from the GLS-detrended to OLS-detrended equation. The second is changing the information criterion from the SIC to MSIC.
Table 1: Output of the Augmented Dickey-Fuller Test for Fees in Tirtonadi Bus Station'

\begin{tabular}{|l|r|r|r|r|}
\hline \multirow{2}{*}{\multicolumn{1}{|c}{ Fees }} & \multicolumn{2}{c|}{ Level Equation } & \multicolumn{2}{c|}{ First-Difference Equation } \\
\cline { 2 - 5 } & \multicolumn{1}{c|}{ Drift } & \multicolumn{1}{c|}{ Drift and Trend } & \multicolumn{1}{c|}{ Drift } & \multicolumn{1}{c|}{ Drift and Trend } \\
\hline LnPassenger (lnPs) & $\begin{array}{r}1.550494 \\
0,346182^{*}\end{array}$ & -0.075379 & $-6.737156^{*}$ & $-7.915399^{*}$ \\
\hline LnLongDistanceBus (lnFd) & $-3.979234^{*}$ & $-4.207287^{*}$ & $-8.580702^{*}$ & $-8.511592^{*}$ \\
\hline LnShortDistanceBus (lnSd) & $-3.901714^{*}$ & $-5.283815^{*}$ & $-11.565680^{*}$ & $-11.467160^{*}$ \\
\hline LnParking (lnPk) & $-7.934812^{*}$ & $-7.936034^{*}$ & $-6.036207^{*}$ & $-6.063793^{*}$ \\
\hline
\end{tabular}

Note: I=All tests are based on the Schwarz Information criterion (SIC), $ب=$ the test is based on the Modified Schwarz Information criterion (MSIC), $=$ the value is similar to the value provided by the PP test, and $*=$ Significant at $1 \%$.

Source: Riyardi et al. 2018

Passenger, Parking, Long-distance bus and Short-distance bus fee. Second, they are obtained efficiently and effectively, stable and growing during a transition time.

The unit root tests tested successfully all of fees. There were the ADF, PP and NP tests. Focusing to Passenger fee tests, three important things to employ unit root tests were found. The first was the importance of the error variance estimator at zero frequency. It makes the PP test was more easy to reject the unit root than the ADF test. The absolute $\mathrm{Zt}$ value of the PP test for Level Equations was higher than $t$ value of the ADF test (See "LnPassenger" of Table 1 and 2). Even, at the First-difference Equations for all fees, the absolute $\mathrm{Zt}$ value of the PP test was higher than the ADF test (See First-difference Equations of Table 1 and 2). Only in several estimations the absolute $\mathrm{Zt}$ were not higher. For example, the $\mathrm{Zt}$ statistic value was similar to the $t$ statistic estimated by the ADF test for the Parking fee unit root tests. (See "LnParking" of Table 1 and 2).

The error variance estimator at zero frequency in the PP test was higher than its error variance estimator. When the error variance estimator at zero frequency was higher than its error variance estimator, the PP test provided higher absolute $\mathrm{Zt}$ statistic than the absolute t statistic provided by the ADF test. As a result, the PP test was easier to reject the root.

The second is the importance of the detrending estimation. It is useful to eliminate the time impact to the trend. Moreover, the test becomes an efficient test. Focusing on the Drift and Trend first-difference Equation, the GLS-detrended AR estimator provided an absolute MZt value that was higher than the $\mathrm{Zt}$ value of the PP test. (See the Drift and Trend First-difference at "Ln Passenger" equation of Table 3). At this case, the Passenger fee root was successfully rejected using the NP test, as the PP test did.

However, this MZt value was not confirmed by others. The MZt value of the Drift and Trend Equation at the First-difference Equation was negative but not significant. Even, The MZt value of the Drift Equation at the Level and the First-difference Equations were positive.

Confirmation was provided by changing to the OLS-detrended AR estimator and MSIC information criterion. This was happened at the First-difference equations. $\mathrm{MZt}$ values are negative and significant (See "LnPassenger" of Table 3).

The third is the importance of an optimal lag selection. The selection is done by information and modified information criterion. We used the SIC and MSIC.

The optimal lag was informed by the SIC for all Equations of ADF, PP and NP unit root tests (See notes below each Table). However, the optimal lag was not informed for the Passenger fee Equation at level of $\mathrm{ADF}$ test and at Level and First-difference of NP test. The optimal lag was provided by
Table 2: Output of the Phillips-Perron Test for Fees in Tirtonadi Bus Station'

\begin{tabular}{|l|r|r|r|r|}
\hline \multirow{2}{*}{\multicolumn{1}{|c|}{ Fees }} & \multicolumn{2}{c|}{ Level Equation } & \multicolumn{2}{c|}{ First-difference Equation } \\
\cline { 2 - 5 } & \multicolumn{1}{c|}{ Drift } & \multicolumn{1}{c|}{ Drift and Trend } & \multicolumn{1}{c|}{ Drift } & \multicolumn{1}{c|}{ Drift and Trend } \\
\hline LnPassenger $(\operatorname{lnPs})$ & $-2.851553^{* * *}$ & $-3.294357^{* * *}$ & $-11.770780^{*}$ & $-13.216350^{*}$ \\
\hline LnLongDistanceBus $(\operatorname{lnFd})$ & $-4.005936^{*}$ & $-4.078469^{*}$ & $-17.223240^{*}$ & $-20.261850^{*}$ \\
\hline LnShortDistanceBus $(\operatorname{lnSd})$ & $-3.728915^{*}$ & $-5.291080^{*}$ & $-34.738210^{*}$ & $-39.526530^{*}$ \\
\hline LnParking $(\operatorname{lnPk})$ & $-7.934812^{* \tau}$ & $-7.936034^{*}$ & $-53.854960^{*}$ & $-56.745080^{*}$ \\
\hline
\end{tabular}

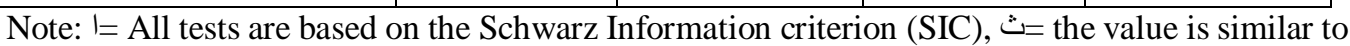
the value provided by the ADF test. $?=$ the error variance coefficient is 0.006916 . It is similar to the error variance at zero frequency coefficient estimated by the Newey West HAC (Bertlett kernel): $0.006916, \tau=$ the error variance coefficient is 0.006850 . It is similar to the error variance at zero frequency coefficient estimated by the Newey West HAC (Bertlett kernel): 0.006850, * ${ }^{*}$ Significant at $1 \%$ and $* * *=$ Significant at $10 \%$.

Source: Riyardi et al. 2018 
the MSIC (See "LnPassenger" of Table 1 and 3).

Our analyses are about persistent fees and unit root tests. The Passenger, Parking, Long Distance Bus and Short Distance Bus fees are persistent fees, although they are confirmed by different unit root tests. The Passenger fee persistence was evaluated by hard unit root tests, while Parking, Long Distance Bus and Short Distance Bus fees persistence was evaluated by easy unit root tests.

The persistent fee finding confirms bus station fees as stated by [13] and [16]. In addition, it is in line to other researches that many transport stations earn fee such as studied by [14]. Moreover, the joint fee confirms different charges found by [15].

Furthermore, features behind fees show that we studied a useful fee. We studied a revenue. It places us in the group that observing time-series microeconomic variables such as [26], [29], [30], [31], [27], [28] and [32].

Confirmation is also attributed to the normal transition time assumption that strengthening to the persistent fees finding. We do not observe the normal transition time but our discussion concludes that it perhaps relate to the future new opportunity and challenge. It is therefore, different from an uncertainty transition time such as analyzed by [21] or [22] Moreover, it offers a new perspective in understanding a transition time.

Another analysis is about unit root tests. We employed three unit root tests that based on the pure time-series data root

Table 3: Output of the Ng-Perron Test for Fees in Tirtonadi Bus Station ${ }^{i}$

\begin{tabular}{|c|c|c|c|c|c|c|c|c|}
\hline \multirow{3}{*}{ Fees } & \multicolumn{8}{|c|}{ Level Equation } \\
\hline & \multicolumn{4}{|c|}{ Drift } & \multicolumn{4}{|c|}{ Drift and Trend } \\
\hline & Mza & MZt & MSB & MPT & Mza & MZt & MSB & MPT \\
\hline LnPassenger (InPs) & 1.033 & 1.356 & 1.313 & 115.930 & $-32.061 *$ & $-4.001 *$ & $0.1248^{*}$ & $2.857 *$ \\
\hline $\begin{array}{l}\text { LnLongDistanceBus } \\
\text { (InFd) }\end{array}$ & $-18.357 *$ & $-3.016^{*}$ & $0.164 *$ & $1.386^{*}$ & $-21.527 * *$ & $-3.278 * *$ & $0.152 * *$ & $4.250^{* *}$ \\
\hline $\begin{array}{l}\text { LnShortDistanceBus } \\
\text { (lnSd) }\end{array}$ & $-17,257 *$ & $-2.921 * *$ & $0.169^{*}$ & $1.481^{*}$ & $-26.089 *$ & $-3.593 *$ & $0.138^{*}$ & $3.604 *$ \\
\hline LnParking (lnPk) & $-29.439 *$ & $-3.827 *$ & $0.130^{*}$ & $0.862^{*}$ & $-29.043 *$ & $-3.833 *$ & $0.130^{*}$ & $3.108 *$ \\
\hline CV $1 \%$ & -13.80 & -2.580 & 0.174 & 1.780 & -23.800 & -3.420 & 0.143 & 4.030 \\
\hline CV 5\% & -8.10 & -1.980 & 0.233 & 3.170 & -17.300 & -2.910 & 0.168 & 5.480 \\
\hline CV $10 \%$ & -5.70 & -1.620 & 0.275 & 4.450 & -14.200 & -2.620 & 0.185 & 6.670 \\
\hline \multirow{3}{*}{ Fees } & \multicolumn{8}{|c|}{ First-difference Equation } \\
\hline & \multicolumn{4}{|c|}{ Drift } & \multicolumn{4}{|c|}{ Drift and Trend } \\
\hline & Mza & MZt & MSB & MPT & Mza & MZt & MSB & MPT \\
\hline LnPassenger $(\operatorname{lnPs})^{2}$ & $\begin{array}{r}0.068 \\
-26.351^{*} \\
\end{array}$ & $\begin{array}{c}0.100 \\
-3,609 *\end{array}$ & $\begin{array}{r}1.472 \\
0.137 *\end{array}$ & $\begin{array}{l}1.151^{*} \\
0.996^{*}\end{array}$ & $\begin{array}{r}-0.288 \\
-27.787 * \\
\end{array}$ & $\begin{array}{r}-0.357 \\
-3,725^{*} \\
\end{array}$ & $\begin{array}{r}1.237 \\
0.134 * \\
\end{array}$ & $\begin{array}{l}2.807 * \\
3.295^{*}\end{array}$ \\
\hline $\begin{array}{l}\text { LnLongDistanceBus } \\
\text { (InFd) }\end{array}$ & $-28.181 *$ & $-3.645^{*}$ & $0.129^{*}$ & $1.211^{*}$ & $-28.818 *$ & $-3.770 *$ & $0.130^{*}$ & $3.313^{*}$ \\
\hline $\begin{array}{l}\text { LnShortDistanceBus } \\
\text { (InSd) }\end{array}$ & $-24.581 *$ & $-3.5019 *$ & $0.143^{*}$ & $1.010^{*}$ & $-24.213^{*}$ & $-3.474 *$ & $0.143 * *$ & $3.797 *$ \\
\hline LnParking (lnPk) & $-281.179 *$ & $-11.845^{*}$ & $0.042^{*}$ & $0.100^{*}$ & $-19.168 * *$ & $-3.074 * *$ & $0.160 * *$ & $4.889 * *$ \\
\hline CV $1 \%$ & -13.800 & -2.580 & 0.174 & 1.780 & -23.800 & -3.420 & 0.143 & 4.030 \\
\hline CV 5\% & -8.100 & -1.980 & 0.233 & 3.170 & -17.300 & -2.910 & 0.168 & 5.480 \\
\hline CV $10 \%$ & -5.700 & -1.620 & 0.275 & 4.450 & -14.200 & -2.620 & 0.185 & 6.670 \\
\hline
\end{tabular}

Note: $\dot{\tau}=$ All of estimations are estimated by the Spectral GLS-detrended AR based on SIC, $د=$ the lower value is estimated by the Spectral OLS-detrended AR based on MSIC, *= Significant at $1 \%$, and **= rejection. They are the ADF, PP and NP tests. There are three important features: the error variance estimation at zero frequency, detrending estimator and optimal lag selection.

Our finding can be compared to other studies. We do not mention the DF GLS or ERS unit root test, but we prefer to mention and examine the NP test, besides the ADF and PP tests. Our preference contradicts to [5]), [7] and [2] that mention the DF GLS or ERS tests, but we are in line to [4], [5], [7] and [2] that mention the NP test. Even, we are in line to [4] and [7] that examine the NP test. Our reason is we are comparing unit root tests. The complete but efficient comparison is comparing among the ADF, PP and NP tests.

Recognizing to the error variance estimation at zero frequency, detrending equation and optimal lag selection is very important when conducting a unit root test. Our finding of the Passenger fee testing informed that the test could be passed when recognizing them. Our finding of recognizing to the error variance estimation at zero frequency informed clearly that the PP test tends to have a higher statistic than ADF test. This can also be found in the [5] and [2].

Our finding of recognizing the detrending estimation relates to NP test. However, our detrending estimation is by OLS-detrended AR estimator, while according to [33], [5] and [7] the standard is by GLS-detrended AR estimator. It means that we performed imperfect NP test.

Our finding of recognizing to the lag selection informed the important of information criterion such as SIC and MSIC. We are benefited by the SIC in almost tests, while we are benefited by the MSIC in the several $\mathrm{ADF}$ and NP tests. However, according to [4], [5], and [7] the information criterion makes sense in the NP test.

Our unit root tests findings place us in the third group to analyze the time-series microeconomics method. We are different from the previous groups in two ways. First, we are different from the first group. We observe single microeconomic variable, while the first group observes microeconomic-conf irmed macroeconomic 
Agung Riyardi et al., International Journal of Emerging Trends in Engineering Research, 7(11), November 2019, 403 - 409

variable. Second, we are different from the second group. We employ time-series unit root tests, while the second group does not employ any unit root test.

Even, we enrich the third group. Our enrichment can be seen from microeconomics and econometrics sides. We enrich the microeconomics side of the third time-series microeconomics group by the joint revenue observation that consists of Passenger, Parking, Long-distance and Short-distance fees observation. It is different from single revenue and single price as studied by [32].

The econometrics side of the time-series microeconomics is enriched. We examine pure time-series data, while other studies prefer panel data such as [29] or [31]. Furthermore, we employ three unit root tests, and we provide error variance estimation at zero frequency, detrending estimation and lag selection analysis, while previous study employ ADF and Phillips-Peron unit root tests such as studied by [30] or the ADF test such as studied by [32].

In addition, our enrichment means that we recognize to the microeconomics theory and data-modelling coherency. It means that we deal to internal and external consistencies. We are an example of a micro foundation such described by [24]. Even, we are the third group of time-series microeconomics that different from especially the micro foundation first group such as [24] or [34].

Moreover, our enrichment means that we consolidate the revenue concept and unit root econometric method. They are an example of the scientific unification in the time-series microeconomics. They can be compared to Location and Growth theories unification in New Economic Geography as described by [35]. Similar as an example of the scientific unification in the economics field, the theory type is different. The revenue fee concept and unit root method are a conceptual-methodological theory, while Location and Growth theories are a conceptual theory.

We recommend to the governmental organization to check its useful fee. Every period, the revenue should be examined by unit root tests. It is to ensure that the revenue is a useful revenue that is obtained efficiently and effectively, a stable and growing revenue from many sources. This is also can be applied to firm that earns economic revenue and profit.

We also recommend to many studies in the future to develop our study and the time-series microeconomics. First is observing other pure microeconomic variable such as a persistent profit, cost, product, or price. Second is observing in other areas under government authority besides a bus station. It can be still in the transportation field such as train station, airport, harbor, road, parking area, or other than transportation field such as electricity, water supply, post office, zoo or tourism area. Third is conducting in the original microeconomics object, a firm. The market setting can be imposed as a strategic assumption. In this case, many interesting economic sectors can be observed. The sectors range from agriculture, manufacturing to service sectors. The research will be better if recognize to consistencies and unification. All of them develop time-series microeconomics and enrich examples of the coherency and theoretical unification.

\section{REFERENCES}

[1] Rusdi, "Uji Akar-akar Unit dalam Model Runtun Waktu Autoregresive," Statistika, vol. 11, no. 2, pp. 67-78, 2011.

[2] A.-C. Petrică, S. Stancu and V. Ghițulescu, "Stationarity-The Central Concept in Time Series Analysis," International Journal of Emerging Research in Management \& Technology, vol. 6, no. 1, pp. 6-16, 2017.

[3] F. X. Diebold and L. Kilian, "Unit Root Tests are Useful for Selecting Forecasting Models," Journal of Business and Economic Statistics, vol. 18, pp. 265-273, 2000.

[4] Atiq-ur-Rehman, "Impact of Model Specification Decisions on Unit Root Tests," International Econometric Review, vol. 3, no. 2, pp. 22-33, 2011.

[5] M. Arltová and D. Fedorová, "Selection of the Unit Root Test on the Basis of Length of the Time Series and Value of AR(1) Parameter," Statistika, vol. 96, no. 3, pp. 47-64, 2016.

[6] d. A. I Maruddani, Tarno and R. Al Anisah, "Uji Stationaritas Data Inflasi dengan Phillips-Perron Test," Media Statistika, vol. 1, no. 1, pp. 27-34, 2008.

[7] S. Guaita, "Revisiting the Unit Root Hypothesis: A Historical and Empirical Study," New School Economic Review, vol. 8, pp. 59-78, 2016.

[8] P. Perron, "Unit Roots and Structural Breaks," Econometrics, vol. 5, no. 22, pp. 1-3, 2017.

[9] N. T. Hoang and R. F. McNown, "Panel Data Unit Root Tests Using Various Estimation Methods," Department of Economics Colorado University, Colorado, 2006.

[10] J. Bai and N. Serena, "Panel Unit Root Tests with Cross-Section Dependence: A Further Investigation," Econometric Theory, vol. 26, pp. 1088-1114, 2010.

[11] J. J. Dolado and T. Jenkinson, "Cointegration and Unit Roots," Journal of Economic Surveys, vol. 4, no. 3, pp. 249-273, 1990.

[12] P. K. Enns, N. J. Kelly, T. Masaki and P. C. Wohlfarth, "Moving forward with time series analysis," Research and Politics, pp. 1-7, October-December 2017.

[13] S. Mathur and A. Smith, "Land value capture to fund public transportation infrastructure: Examination of joint development projects' revenue yield and stability," Transport Policy, vol. 30, pp. 327-335, 2013.

[14] C. Ferrari, P. P. Puliafito and A. Tei, "Port Terminal Concessions: Towards a Dynamic Concession Fee," Journal of Transport Economics and Policy, vol. 52, no. 2, pp. 137-156, 2018.

[15] J. Zuidberg, "Key Drivers for Differentiated Airport Passenger Service Charges," Journal of Transport Economics and Policy, vol. 48, no. 2, pp. 279-295, 2014.

[16] A. Riyardi, Sujadi and Triyono, "Efficiency and Effectiveness of The Tirtonadi Bus Station Retribution 
Agung Riyardi et al., International Journal of Emerging Trends in Engineering Research, 7(11), November 2019,403 - 409

Charging During the Transition time: Pragmatic and Parametric Methods," in 14th Irsa International Conference, Surakarta, 2018.

[17] R. Talib, M. Z. Sulieman and R. Prihatmanti, "So you think you can handle a successful homestay? Case Study: Kota Aur, Malaysia," International Journal of Emerging Trends in Engineering Research, vol. 6, no. 8, pp. 46-52, 2018.

[18] Fransisco D. Esponilla II, J. P. Alinsunod, H. T. Ignacio, H. C. d. Guzman, E. L. G. Borjal, K. C. D. Cruz and I. C. Valenzuela, "Issues and Challenges of Technology Business Incubators in the Philippines," International Journal of Emerging Trends in Engineering Research, vol. 7, no. 9, pp. 353-359, 2019.

[19] Y. P. Deshmukh and A. B. Borade, "Performance evaluation of the Indian plastic processors supply chain: Implementing lean and green philosophies," International Journal of Emerging Trends in Engineering Research, vol. 7, no. 5, pp. 1-14, 2019.

[20] Caryl Charlene Escolar-Jimenez, K. Matsuzaki, K. Okada and R. C. Gustilo, "Data-Driven Decisions in Employee Compensation utilizing a Neuro-Fuzzy Inference System," International Journal of Emerging Trends in Engineering Research, vol. 7, no. 8, pp. 163-169, 2019.

[21] S. Suleymanli, "Common challenges in Public Sector Performance Measurement in Post-Soviet Countries Remedies Taken to Escape from the Soviet Legacy," Khazar Journal of Humanities and Social Sciences, vol. 21, no. 1, pp. 23-33, 2018.

[22] N. E. Rahman, "Traditional Bureaucratic Culture as an Impending Factor in Implementing New Public Management in Bangladesh," South Asian Journal of Social Studies and Economics, vol. 1, no. 1, pp. 1-6, 2018.

[23] A. Assadian and R. Cebula, "Determinants of Business Failure: A Time Series Analysis," Munich Personal RePEc Archive, Munchen, 1989.

[24] S. Wren-Lewis, "Internal Consitency, Price Rigidity, and the Microfoundations of Macroeconomics," Journal of Economic Methodology, vol. 18, pp. 129-146, 2011.

[25] S. Wang, F. Yang, X. Wang and J. Song, "A Microeconomics Explanation of the Environmental Kuznets Curve (EKZ) and an Empirical Investigation," Pol. J. Environ. Stud., vol. 26, no. 4, pp. 1757-1764,
2017.

[26] S. J. Koopman and M. Ooms, "Time Series Modelling of Daily Tax Revenue," Tinbergen Institute, Amsterdam, 2001.

[27] Oregon Department of Transportation, "Transportation Revenue Forecast Model: Methodology Overview," Oregon Department of Ttransportation, Oregon, 2015.

[28] M. Puziak, "The Persistance of Abnormal Returns: Analysis of Polish Manufacturing Industry," Economics and Sociology, vol. 10, no. 1, pp. 48-60, 2017.

[29] S. Bond, C. Nauges and F. Windmeijer, "Unit Roots: Identification and Testing in Micro Panels," Centre for Microdata Methods and Practice, London, 2005.

[30] A. Barbara and Carrasco-Terrazas, "The Microeconomics of Fixed Costs and The Impact of Operating Leverage on US Lodging Stock Return," Stockholm School of Economics, Stockholm, 2006.

[31] F. Zeren and E. Öztürk, "Testing for Profit Persistence of Listed Manufacturing Companies in Istambul Stock Exchange," ЕКОНОМИКА, vol. 61, no. 2, pp. 1-10, 2015.

[32] R. B. Porto, R. d. R. Costa and E. A. d. M. Watanabe, "The Multilevel Effect of Marketing Activities on Sales, Revenue, and Profitability in a Micro-entrerprise," Review of Business Management, vol. 19, no. 65, pp. 432-452, 2017.

[33] M. I. Malik and Atiq-ur-Rehman, "Choice of Spectral Density Estimator in Ng-Perron Test: A Comparative Anlysis," International Econometrics Review, pp. 51-63, 2015.

[34] S. Wren-Lewis, "Ending the Microfoundations Hegemony," Oxford Review of Economic Policy, vol. 34, no. 1-2, pp. 55-69, 2018.

[35] C. Marchionni, "Scientific Unification in Economics. The Case of the New Economics Geography," Humana.Mente, no. 10, pp. 11-24, July 2009. 